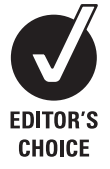

${ }^{1}$ Cardiff Institute of Society, Health and Ethics, Cardiff University, Cardiff, UK; ${ }^{2}$ Department of Psychology, Swansea University, Swansea, UK

Correspondence to: Professor L Moore, Cardiff Institute of Society, Health and Ethics, 53 Park Place, Cardiff University, Cardiff CF10 3AT, UK; MooreL1@cardiff.ac.uk

Accepted 22 February 2008

\title{
The impact of school fruit tuck shops and school food policies on children's fruit consumption: a cluster randomised trial of schools in deprived areas
}

\author{
L Moore, ${ }^{1}$ K Tapper ${ }^{2}$
}

\begin{abstract}
Aims: To estimate the impact of school fruit tuck shops on children's consumption of fruit and sweet and savoury snacks.
\end{abstract}

Design: Cluster randomised effectiveness trial with school as the unit of randomisation.

Setting: 43 primary schools in deprived areas in south Wales and south-west England with a range of school food policies.

Intervention: Schools operated fruit tuck shops throughout one academic year. Control schools did not do so.

Measures: Repeated cross-sections of children aged 911 years completed a computerised 24-hour recall questionnaire at baseline $(n=1902)$ and at 1 -year followup $(n=1924)$, when a brief questionnaire was also completed ( $n=1976)$.

Results: Approximately 70000 fruits were sold in the 23 intervention schools over the year, equivalent to 0.06 fruits per student per day. Children in intervention schools were more likely to report eating fruit as a snack at school 'often' (OR 1.49, 95\% Cl 1.15 to 1.95). There were no significant differences in children's intake of fruit or other snacks. There was a significant interaction $(p<0.02)$ between the intervention group and school food policy: where students were only allowed to bring fruit to school, fruit consumption was 0.37 portions per day 10.11 to 0.64) higher in intervention schools, compared to 0.14 portions $(-0.30$ to 0.58$)$ where no food was allowed and -0.13 portions $(-0.33$ to 0.07$)$ where there were no restrictions.

Conclusions: In isolation, fruit tuck shops were not effective in changing children's snacking behaviour in schools. However, the results suggest that fruit tuck shops had a greater impact when reinforced by school policies restricting the types of foods students were allowed to bring to school.

In recent years there has been increasing concern about the diets of British school children. ${ }^{1}$ In response to this and the associated concern regarding child obesity, the UK government has introduced a number of measures aimed at improving children's diets, including the introduction of initiatives designed to increase consumption of fruit and vegetables. ${ }^{2}$

In some instances, good-quality fruit and vegetables are simply not readily available, ${ }^{3-5}$ and it is therefore assumed that interventions to tackle problems of availability or affordability will lead to increased consumption. Such initiatives have included the introduction of nutritional standards for food provided in schools ${ }^{6}$ and the provision of free fruit for 4-7 year olds. ${ }^{7}$

The view that fruit and vegetable consumption is partially dictated by availability is consistent with the fact that those on low incomes, who lack easy access to these foods, tend to have poorer diets. ${ }^{57}$ A number of studies have also shown that availability of fruit and vegetables predicts, or is positively associated with, levels of consumption. ${ }^{8-}$ ${ }^{14}$ Unfortunately, very little experimental research has examined the impact of fruit and vegetable availability on consumption. The evaluation of intervention programmes aimed at increasing consumption usually employs experimental study designs. However, these tend to include availability as just one of a number of different intervention components and do not assess its effects separately. ${ }^{15-20}$ Thus, where these interventions have been successful, it has been unclear to what extent, if any, this was due to increased availability.

A limited number of studies have directly examined the effects of increased fruit and vegetable availability on consumption and the results of some of these have been promising. In Denmark, primary schools piloted a fruit 'subscription' scheme whereby 6-10 year olds whose parents subscribed to the scheme were provided with one portion of fruit or vegetables each day. Research showed that 5 weeks after the introduction of the scheme, fruit consumption had increased by 0.4 pieces per school day among children who subscribed and by 0.3 pieces among non-subscribers. ${ }^{21}$ In Norway, where schoolchildren have been provided with free fruit and vegetables, research has also shown increases in consumption. ${ }^{22-24}$ Three years after the introduction of this scheme, estimated increases in consumption were 0.38 portions per day for boys and 0.44 portions per day for girls. ${ }^{24}$

However, other studies examining the long-term effects of increased availability of healthy foods have not been as positive. In English secondary schools, increasing the availability of healthy foods at lunchtime did not have significant, sustained effects on consumption of these foods when assessed over a 2-year period. ${ }^{25}$ In primary schools, provision of free fruit resulted in no increases in consumption after 20 months. ${ }^{26}$ And in American middle schools, provision of low-fat foods in school food outlets (combined with a limited amount of promotion) had no effect on fat intake when it was measured 2 years after the introduction of the changes. $^{27}$ 
In addition, we know little about the mechanisms by which food availability impacts upon consumption. In some instances, it may be that consumption levels are restricted by a lack of availability and thus by increasing availability one simply removes this barrier. However, it is also possible that availability influences consumption via other variables such as group norms and preferences. ${ }^{28-38}$ Thus, although increasing fruit and vegetable availability within the school environment might initially only raise consumption among a minority of children, it is possible that such changes would eventually occur among other children due to processes of peer influence and taste exposure.

The present study examines the impact of school fruit tuck shops on children's diets. Fruit tuck shops can be an effective way of making fruit readily available to children. They require limited investment from government and are a relatively lowmaintenance and sustainable initiative for schools. For these reasons, they are becoming increasingly popular as part of a drive towards healthy eating. ${ }^{39}$ However, to date their effectiveness in terms of dietary change has not been examined. The present study employs a randomised controlled trial design to examine their impact on children's consumption of both fruit and other sweet and savoury snacks.

\section{METHOD}

\section{Participants and recruitment}

Two hundred and fifty-five primary and junior schools in eight local education authorities in south-west England and south Wales were identified as having a free school meal entitlement higher than the national average of 17 per cent. These schools were contacted regarding tuck shop provision. If there was an existing tuck shop, selling any type of food, the school was excluded. The remaining 142 schools were asked if they would be willing to participate in the study, bearing in mind that there was a 50 per cent chance that they would be randomised to the control condition. Forty-three schools agreed to participate and were each promised a $£ 50$ donation on completion of the study to compensate for disruption to school activities. Prior to the study, letters were sent to parents informing them of the research and giving them the opportunity to withdraw their child from the data collection. Figure 1 shows the flow of schools and students through the study.

\section{Sample size}

Previous research indicated that primary school children in low income areas of south-west England consumed an average of 0.75 portions of fruit per day. ${ }^{40}$ Assuming an average of 50 children per school, and intracluster correlations within schools of 0.02 , a power calculation indicated that a sample size of 42 schools would provide 80 per cent power to detect a 25 per cent difference in fruit consumption between intervention and control schools.

\section{Randomisation}

After all 43 schools had been recruited, they were allocated to control and experimental groups using sequential minimisation applied to the schools in random order. Minimisation variables were school size (above or below 40 children in Year 6), country (England or Wales), existing policy on snacks at morning break (no food, fruit only or no restrictions) and expressed preference for allocation (preference for control, preference for intervention or no preference). Given the nature of the intervention, teachers, children and researchers were not blind to group allocation.

Throughout the study, both intervention and control schools were asked to continue with their existing curriculum and school meal arrangements. Intervention schools set up tuck shops that were not subsidised in any way, although some support and advice was available to schools from a project support officer. Schools were asked to offer a choice of fruit in the tuck shop, to price each item at 15 pence and to refrain from stocking sweets, crisps and other items as alternatives. Other than this, schools were relatively free to choose how they operated the tuck shop and this resulted in a variety of different approaches, which are described elsewhere. ${ }^{39}$

\section{Measures}

The primary outcome measure was consumption of fruit and other sweet and savoury snacks, assessed using a single-day computerised 24-hour recall questionnaire completed by children. Previous research indicated that this measure showed acceptable levels of validity, reliability and sensitivity. ${ }^{40}$ The questionnaire recorded the number of servings of (a) fruit, (b) sweets, chocolate and biscuits, and (c) crisps consumed during the previous 24-hour period. For each of these three food types, two measures were computed: the number of servings consumed at school and the number of servings consumed throughout the whole day. All intervention schools were also asked to keep a weekly record of fruit tuck shop sales throughout the 9-month period.

Secondary outcomes were collected at follow-up only, using a brief pencil and paper questionnaire. These assessed whether the tuck shops influenced children's preference for fruit and their peer group norms regarding fruit. This questionnaire was also used as a means of identifying any small changes in fruit consumption that the computerised questionnaire may not have been sensitive enough to detect. Prior to its use, the questionnaire was piloted in a primary school that was not involved in the study and the final version of the questionnaire consisted of a series of closed questions to which children responded with one of two or three alternatives (see Results section).

\section{Procedure}

The computerised questionnaire was administered prior to the introduction of the tuck shops in the intervention schools (summer term, 1999) and at follow-up. The brief questionnaire was administered at follow-up only. On both occasions, one class of Year 5 children and one class of Year 6 children were randomly selected from each school to complete the questionnaire(s). Thus the study employed a repeated cross-section design, although many of the Year 5 children who provided data at baseline were resurveyed at follow-up. On data collection days, laptop computers were set up in each school and children participated in groups of four or five. Two researchers were present to assist with any difficulties they had.

\section{Data analysis}

Primary outcomes were analysed using school level regression analysis. For each of the six outcomes, the baseline measure for each school was used as a covariate, in addition to the four minimisation variables. Models were estimated using weights calculated according to the formula described by Donner and Klar. ${ }^{41}$ Secondary outcomes only collected at follow-up were analysed using random effects logistic regression. ${ }^{42}$ Items with 
Figure 1 Flow of schools and students through the study.

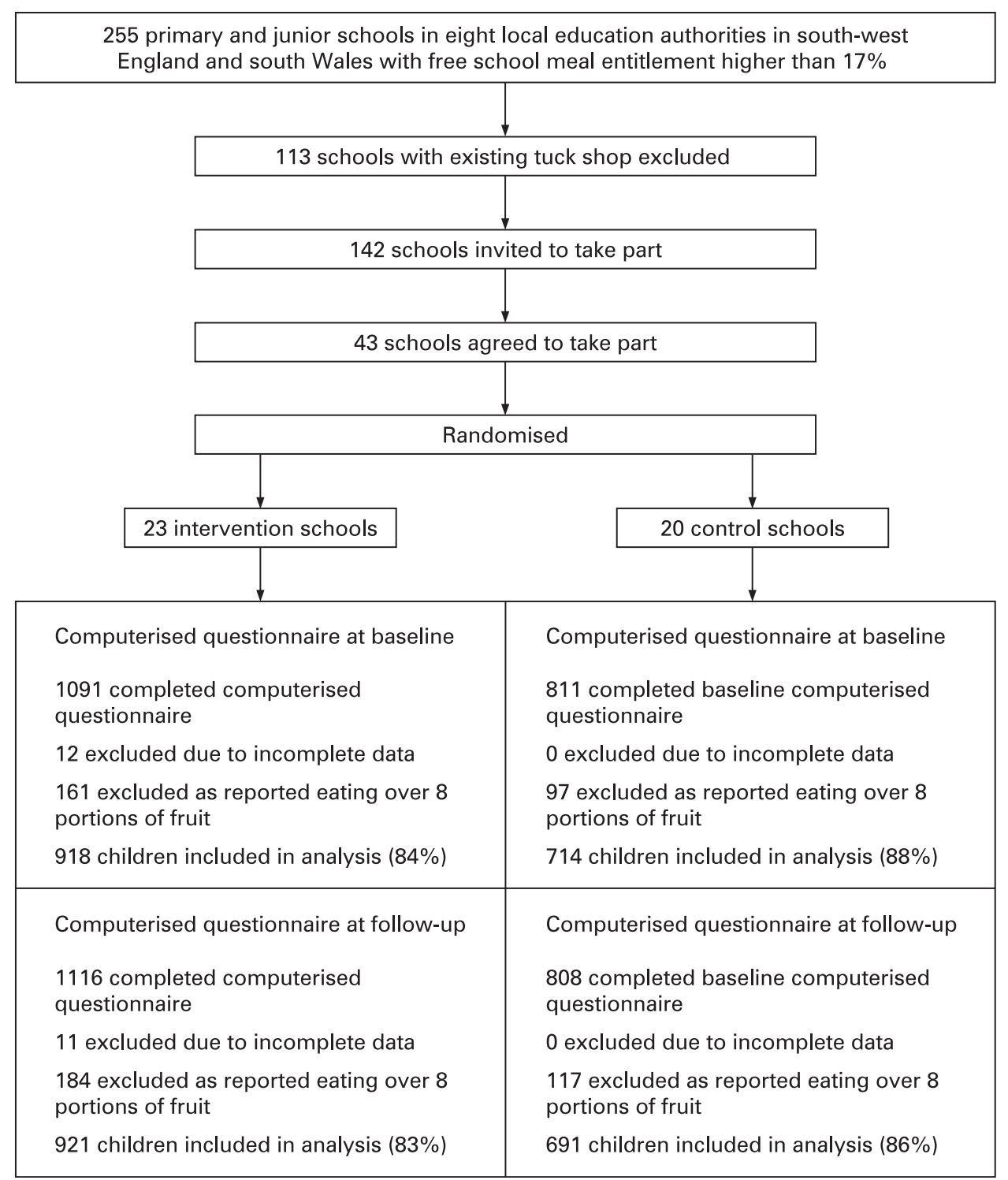

three alternative responses were dichotomised and the four minimisation variables were included as covariates.

\section{RESULTS}

\section{Computerised questionnaire measure}

A total of 1902 children completed the questionnaire at baseline. However, 12 children did not provide complete data, and a further 258 were excluded as they reported eating over eight servings of fruit. ${ }^{40}$ This left a total of 1632 children; 918 in the 23 intervention schools and 714 in the 20 control schools (see fig 1). Baseline characteristics were evenly distributed between the control and intervention groups (table 1).

A total of 1924 children completed the questionnaire at follow-up, of which 1612 were included in analysis: 921 intervention students and 691 control (see fig 1). Reported levels of fruit and snack intake at follow-up are displayed in table 2. These showed that in the intervention schools, children consumed an average of 0.74 servings of fruit at school and 2.54 servings throughout the whole 24 -hour period. In the control schools, children consumed an average of 0.69 servings of fruit at school, and 2.51 servings throughout the whole 24-hour period. Consumption of other snacks was also similar across the intervention and control schools. For example, at school, children in the intervention schools consumed an average of 1.12 servings of sweets, chocolate and biscuits and 0.80 servings of crisps, whereas in the control schools they consumed an average of 1.01 servings of sweets, chocolate and biscuits and 0.68 servings of crisps.

The results of the school level regression models are shown in table 3. For all six outcomes the intervention effect estimates were near zero, and the $95 \%$ confidence intervals were distributed fairly symmetrically over the null effect. Thus overall, the tuck shops had no effect on children's consumption of fruit or other snacks. It is also important to note that the confidence intervals were not wide (generally 0.3 serving), indicating that the absence of a statistically significant effect was not due to a lack of power.

The data were then tested for interactions with school policy. Of the six analyses conducted there was a significant interaction effect only for fruit consumed at school, $\mathrm{F}(2,32)=4.55, \mathrm{p}<0.02$. In this model, estimates of the difference in fruit consumption between intervention and control school students were 0.37 portions (95\% CI 0.11 to 0.64 ) greater consumption among schools with a fruit only policy; 0.14 ( -0.30 to 0.58$)$ with a no 
Table 1 Baseline school and student characteristics and reported levels of fruit and snack intake

\begin{tabular}{lll}
\hline & $\begin{array}{l}\text { Intervention } \\
\mathbf{n}(\%)\end{array}$ & $\begin{array}{l}\text { Control } \\
\mathbf{n}(\%)\end{array}$ \\
\hline $\begin{array}{l}\text { School location } \\
\text { England }\end{array}$ & $496(54.0)$ & $423(59.2)$ \\
$\quad$ Wales & $422(46.0)$ & $291(40.8)$ \\
School food policy & & \\
$\quad$ No food & $97(10.6)$ & $76(10.6)$ \\
Fruit only & $235(25.6)$ & $216(30.3)$ \\
$\quad$ No restrictions & $586(63.8)$ & $422(59.1)$ \\
School size & & \\
$\quad<40$ students in Year 6 & $509(55.4)$ & $355(49.7)$ \\
$>40$ students in Year 6 & $409(44.6)$ & $359(50.3)$ \\
Sex & & $339(47.5)$ \\
$\quad$ Boys & $456(49.7)$ & $375(52.5)$ \\
$\quad$ Girls & $462(50.3)$ & Mean (median) \\
Servings consumed at school & Mean (median) & $0.68(0)$ \\
$\quad$ Fruit & $0.62(0)$ & $1.09(1)$ \\
Sweets, chocolate, biscuits & $1.14(1)$ & $0.67(1)$ \\
Crisps & $0.73(1)$ & $2.50(2)$ \\
Servings consumed in 24 hours & & $3.68(3)$ \\
$\quad$ Fruit & $2.48(2)$ & $1.41(1)$ \\
Sweets, chocolate, biscuits & $3.98(3)$ & \\
Crisps & $1.53(1)$ & \\
\hline
\end{tabular}

food policy, and -0.13 ( -0.33 to 0.07 ), that is 0.13 fewer portions in those with no restrictions on food brought to school.

\section{Fruit tuck shop sales}

For many schools, the maintenance of the tuck shop sales records proved to be more onerous than the operation of the tuck shops themselves. It was decided that the continued cooperation of schools (and operation of tuck shops) should not be jeopardised by strict enforcement of the quality and timeliness of the weekly sales record data. Thus, a detailed analysis of the sales data was not undertaken. Over the 23 schools, there were 5600 students on the school rolls, which over an academic year totals approximately 1.1 million student school days. Fruit sales over the year in the 23 intervention schools were estimated to have been in the region of 70000 fruits. This is the equivalent of 0.06 fruits per student per day, which in turn equates to approximately 1 in 4 children eating one piece of fruit per week, or 1 in 17 eating fruit every day. In general, fruit sales were highest in the first term of operation (autumn term, 1999) and then declined, both as the autumn term progressed and during the spring and summer terms. By the end of the summer term, four out of the 23 tuck shops were permanently or temporarily closed.

\section{Brief questionnaire measure}

The brief questionnaire was completed by 1976 children. Table 4 shows the odds ratios from the random effects regression models for the association between intervention group and a positive response to each question.

Table 4 indicates that, with the exception of the final item, children in schools with fruit tuck shops were more likely to give positive responses to the items on the questionnaire. In relation to fruit consumption, children in intervention schools were significantly more likely to state that they would use a tuck shop $(p<0.002)$ and were significantly more likely to state that they often ate fruit as a snack at school $(p<0.005)$.
Table 2 Reported levels of fruit and snack intake in intervention and control schools at follow-up

\begin{tabular}{lll}
\hline & $\begin{array}{l}\text { Intervention mean } \\
\text { (median) }\end{array}$ & $\begin{array}{l}\text { Control mean } \\
\text { (median) }\end{array}$ \\
\hline $\begin{array}{l}\text { Portions consumed per day at school } \\
\quad \text { Fruit }\end{array}$ & $0.74(0)$ & $0.69(0)$ \\
$\quad$ Sweets, chocolate, biscuits & $1.12(1)$ & $1.01(1)$ \\
Crisps & $0.80(1)$ & $0.68(1)$ \\
Portions consumed in 24 hours & & \\
Fruit & $2.54(2)$ & $2.51(2)$ \\
$\quad$ Sweets, chocolate, biscuits & $3.95(3)$ & $3.81(3)$ \\
Crisps & $1.60(1)$ & $1.45(1)$ \\
\hline
\end{tabular}

The data were then tested for one interaction, which was that between the fruit tuck shop intervention and school food policy. Of the seven analyses conducted, the results showed a significant effect for question 6 ('How many of your friends eat fruit?'), $\chi^{2}(2)=9.99, p<0.01$. Consistent with predictions, odds ratios for tuck shop versus no tuck shop schools were higher for those with a no food policy $(4.44,95 \%$ CI 1.96 to 10.0$)$ ) or a fruit only policy $(1.35,95 \%$ CI 0.82 to 2.23$)$ compared with those with no food restrictions $(1.05,95 \%$ CI 0.75 to 1.47$)$. For question 2 ('Do you eat fruit as a snack at school?') although the interaction test was less significant, $\chi^{2}(2)=3.87, p=0.14$, the same pattern was apparent with odds ratios for the intervention effect higher among schools with a no food policy $(2.41,95 \% \mathrm{CI}$ 1.12 to 5.19$)$ or a fruit only policy $(1.89,95 \%$ CI 1.19 to 3.01$)$ than those with no food restrictions $(1.21,95 \%$ CI 0.88 to 1.67$)$.

\section{DISCUSSION}

The present study examined the impact of a school fruit tuck shop scheme on the diets of children aged 9-11 years. A major strength of the study is that an unbiased estimate of the effect of the intervention when implemented in real-world conditions has been identified, using a strong scientific research design. The trial was an effectiveness trial, which allowed variation in the implementation of the fruit tuck shops across schools in a way that would probably occur in the real-world implementation of such a policy. ${ }^{43}$ Although this meant that some intervention schools did not operate fruit tuck shops throughout the year, all schools succeeded in introducing a low-cost fruit tuck shop, and none of the tuck shops sold sweets or crisps. A paper based on the process evaluation conducted alongside the trial documents the variety of ways in which the tuck shops were implemented and identifies models of good practice. ${ }^{39}$ As a pragmatic effectiveness trial, the results are directly relevant to large-scale attempts to employ fruit tuck shops as a means of improving children's diet. A limitation of the study was that although the tuck shops were introduced to the whole primary school (5-11 years), because of the difficulties associated with obtaining accurate dietary information from young children ${ }^{44}$ consumption measures were taken with children aged 9-11 years only. A further limitation was the reliance on self-report measures of fruit consumption collected using a computerised questionnaire. These measures were found to have relatively poor validity at the individual level when used to measure fruit and snack consumption over a 24-hour period. Nevertheless, when restricted to children's fruit consumption in school it demonstrated reasonable validity and reliability, ${ }^{40}$ with 7 per cent omissions and 12 per cent intrusions compared with a dietary recall interview. Similarly, at the group level, the focus of analysis in this paper, the measure demonstrated adequate reliability and sensitivity to identify differences between groups, 
Table 3 Multivariable models of fruit and snack consumption in schools $(n=43$ ) at follow-up (95\% confidence intervals)

\begin{tabular}{llll}
\hline & \multicolumn{1}{c}{ Fruit } & \multicolumn{1}{c}{ SCB } & \multicolumn{1}{c}{ Crisps } \\
\hline $\begin{array}{l}\text { Portions per day consumed at school } \\
\text { Intervention vs control }\end{array}$ & $+0.057(-0.100$ to 0.213$)$ & $-0.116(-0.289$ to 0.056$)$ & $-0.047(-0.153$ to 0.060$)$ \\
Baseline consumption & $+0.330(-0.086$ to 0.746$)$ & $+0.684(0.403$ to 0.966$)$ & $+1.062(0.804$ to 1.319$)$ \\
Wales vs England & $-0.127(-0.029$ to 0.283$)$ & $-0.009(-0.189$ to 0.165$)$ & $+0.001(-0.104$ to 0.106$)$ \\
Large vs small & $+0.033(-0.130$ to 0.196$)$ & $+0.076(-0.108$ to 0.260$)$ & $-0.012(-0.098$ to 0.122$)$ \\
Fruit only vs no food & $-0.029(-0.212$ to 0.154$)$ & $-0.211(-0.418$ to -0.004$)$ & $+0.030(-0.124$ to 0.183$)$ \\
$\quad$ No restrictions vs no food & $+0.016(-0.247$ to 0.279$)$ & $-0.005(-0.307$ to 0.297$)$ & $-0.024(-0.219$ to 0.171$)$ \\
Portions consumed in 24 hours & & & \\
$\quad$ Intervention vs control & $+0.089(-0.199$ to 0.377$)$ & $-0.137(-0.527$ to 0.255$)$ & $-0.036(-0.249$ to 0.177$)$ \\
Baseline consumption & $+0.372(0.053$ to 0.691$)$ & $+0.064(-0.223$ to 0.351$)$ & $+0.624(0.264$ to 0.984$)$ \\
Wales vs England & $+0.304(0.018$ to 0.590$)$ & $-0.038(-0.423$ to 0.348$)$ & $+0.206(-0.006$ to 0.418$)$ \\
Large vs small & $+0.114(-0.183$ to 0.411$)$ & $-0.084(-0.493$ to 0.325$)$ & $-0.053(-0.274$ to 0.168$)$ \\
Fruit only vs no food & $+0.097(-0.236$ to 0.431$)$ & $-0.113(-0.562$ to 0.335$)$ & $-0.153(-0.417$ to 0.111$)$ \\
No restrictions vs no food & $-0.062(-0.513$ to 0.389$)$ & $+0.163(-0.456$ to 0.783$)$ & $-0.160(-0.522$ to 0.203$)$ \\
\hline
\end{tabular}

although proved inadequately precise to identify the small estimated differences between groups as being statistically significant.

Although overall no statistically significant impact on children's consumption of fruit, sweets, chocolate, biscuits and crisps was found, there was a statistically significant effect across all schools on children reporting that they often ate fruit as a snack at school. The magnitude of estimated impact on fruit consumption in schools (0.06 fruits per student per day) was consistent with the level of recorded fruit tuck shop sales.

Further analysis of the data revealed a significant interaction between the intervention condition and school food policy. That is, in schools with a 'no food' or 'fruit only' policy the fruit tuck shop intervention had a greater impact than in schools with no restrictions. This was apparent for fruit intake at school measured by both the computerised and the paper questionnaires, and awareness of friends' regular consumption of fruit. Thus, overall, the findings indicate that when introduced in isolation the tuck shops were likely to have had a limited impact on fruit consumption at school. However, when employed in conjunction with appropriate school policies their impact was more significant.

Similarly fruit only policies, in isolation, have not been found to increase children's consumption of fruit, ${ }^{40} 45$ although restriction of foods allowed in school has been found to be associated with reduced consumption of foods high in fats and

Table 4 Children's responses to the brief questionnaire in intervention versus control schools

\begin{tabular}{lll}
\hline Item & $\begin{array}{l}\text { Odds ratio (95\% } \\
\text { confidence interval) }\end{array}$ & $\begin{array}{l}\text { p Value (Wald } \\
\text { test) }\end{array}$ \\
\hline $\begin{array}{l}\text { 1. Would you use a tuck shop at your } \\
\text { school? Yes vs no }\end{array}$ & $2.00(1.28$ to 3.12$)$ & 0.002 \\
$\begin{array}{l}\text { 2. Do you eat fruit as a snack at school? } \\
\text { Often vs sometimes or not at all }\end{array}$ & $1.49(1.15$ to 1.95$)$ & 0.003 \\
$\begin{array}{l}\text { 3. What would you choose for a snack } \\
\text { at playtime? Fruit vs chocolate or crisps }\end{array}$ & $1.22(0.85$ to 1.76$)$ & 0.278 \\
$\begin{array}{l}\text { 4. Do you eat fruit as a snack at home? } \\
\text { Often vs sometimes or not at all }\end{array}$ & $1.10(0.87$ to 1.39$)$ & 0.415 \\
$\begin{array}{l}\text { 5. Do you like the taste of fruit? A lot vs } \\
\text { a little or no }\end{array}$ & $1.01(0.83$ to 1.25$)$ & 0.893 \\
$\begin{array}{l}\text { 6. How many of your friends eat fruit? } \\
\text { Most vs some or none }\end{array}$ & $1.33(0.99$ to 1.78$)$ & 0.056 \\
$\begin{array}{l}\text { 7. Do you think it is cool to eat fruit? Yes } \\
\text { vs no }\end{array}$ & $0.95(0.71$ to 1.26$)$ & 0.709 \\
\hline
\end{tabular}

sugars. ${ }^{40}{ }^{46}$ Together these results suggest that where children and their friends are not allowed to bring unhealthy snacks to school, their willingness to utilise the fruit tuck shops and eat fruit as a snack in school is greatly enhanced. These results highlight the importance of supporting school health interventions with appropriate school policies and are consistent with socio-ecological models of behaviour change ${ }^{47}$ that support the value of mutually reinforcing multilevel comprehensive interventions. $^{48} 49$

Acknowledgements: LM was responsible for the study design, data analysis and overall coordination of the project. He also helped revise the manuscript. KT drafted the manuscript and both authors read and approved the final version.

Funding: This study was funded by the Food Standards Agency Food Choice Programme. Anne Dennehy and Joanna Moe led the data collection and intervention activities respectively. LM is supported by a Career Scientist Award funded by the Welsh Assembly Government.

Competing interests: None.

\section{REFERENCES}

1. Department of Health. National diet and nutrition survey: young people aged 4 to 18 years, vol.1. Report of the diet and nutrition survey. London: The Stationery Office, 2000.

2. Department of Health. Choosing health. Making healthy choices easier. London: The Department of Health, 2004.

3. Turner S, Mayall B, Mauthner M. One big rush: dinner time at school. Health Educ J 1995;54:18-27.

4. Baranowski T, Domel S, Gould R, et al. Increasing fruit and vegetable consumption among 4th and 5th grade students - results from focus groups using reciprocal determinism. J Nutr Educ 1993;25:114-120.

5. Lang T, Caraher M. Access to healthy foods: part II. Food poverty and shopping deserts: what are the implications for health promotion policy and practice? Health Educ J 1998:57:202-11.

6. Department for Education and Science. Nutritional standards for school lunches and other school food. http://www.schoolfoodtrust.org.uk (accessed 2 Apr 2008).

7. Department of Health. The national school fruit scheme. DoH: London, 2000.

8. Bere E, Klepp K-I. Correlates of fruit and vegetables intake among Norwegian schoolchildren: parental and self-reports. Public Health Nutr 2004:7:991-8.

9. Bere $\mathbf{E}$, Klepp K-I. Changes in accessibility and preferences predict children's future fruit and vegetables intake. Int J Behav Nutr Phys Act 2005;2:15.

10. Cullen KW, Baranowski T, Owens E, et al. Availability, accessibility, and preferences for fruit, $100 \%$ fruit juice, and vegetables influence children's dietary behaviour. Health Educ Behav 2003;30:615-26.

11. Cullen KW, Baranowski T, Rittenberry L, et al. Child-reported family and peer influences on fruit, juice and vegetable consumption: reliability and validity of measures. Health Educ Res 2001;16:187-200.

12. Neumark-Sztainer D, Wall M, Perry C, et al. Correlates of fruit and vegetable intake among adolescents. Findings from Project EAT. Prev Med 2003;37:198-208.

13. Rasmussen M, Krolner R, Klepp K-I, et al. Determinants of fruit and vegetable consumption among children and adolescents: a review of the literature. Part 1. Quantitative studies. Int J Behav Nutr Phys Act 2006:3:22. 
14. Reynolds KD, Hinton AW, Shewchuk RM, et al. Social cognitive model of fruit and vegetable consumption in elementary school children. J Nutr Educ 1999;31:23-30.

15. Baranowski T, Davis M, Resnicow K, et al. Gimme 5 Fruit, juice, and vegetables for fun and health: outcome evaluation. Health Educ Behav 2000;27:96-111.

16. Domel SB, Baranowski T, Davies H, et al. Development and evaluation of a school intervention to increase fruit and vegetables consumption among 4th and 5 th grade students. Soc Nutr Educ 1993;25:345-9.

17. Foester SB, Gregson J, Beall DL, et al. The California children's 5 a day - power play! campaign: evaluation of a large-scale social marketing initiative. Fam Community Health 1998;21:46-64.

18. Nicklas TA, Johnson CC, Myers L, et al. Outcomes of a high school programme to increase fruit and vegetable consumption: gimme 5 - a fresh nutrition concept for students. J Sch Health 1998;68:248-53.

19. Perry CL, Bishop DB, Taylor G, et al. Changing fruit and vegetable consumption among children: the 5-a-day power plus program in St. Paul, Minnesota. Am J Public Health 1998;88:603-609.

20. Reynolds KD, Franklin FA, Binkley D, et al. Increasing fruit and vegetable consumption of fourth-graders: results from the High 5 Project. Prev Med 2000;30:309-19.

21. Eriksen K, Haraldsdottir J, Pederson R, et al. Effect of a fruit and vegetable subscription in Danish schools. Public Health Nutr 2003;6:57-63.

22. Bere E, Veierod MB, Klepp K-I. The Norwegian School Fruit Programme: evaluating paid vs. no-cost subscriptions. Prev Med 2005:41:463-70.

23. Bere $\mathbf{E}$, Veierod MB, Bjelland $\mathbf{M}$, et al. Free school fruit - sustained effect 1 year later. Health Educ Res 2006;21:268-75.

24. Bere $\mathbf{E}$, Veierod MB, Skare 0, et al. Free school fruit - sustained effect three years later. Int J Behav Nutr Phys Act 2007:4:5

25. Parker L, Fox A. The Peterborough Schools Nutrition Project: a multiple intervention programme to improve school-based eating in secondary schools. Public Health Nutr 2001;4:1221-8.

26. Wells L, Nelson M. The National School Fruit Scheme produces short-term but not longer-term increases in fruit consumption in primary school children. Br J Nutr 2005; 93:537-42.

27. Sallis JF, McKenzie TL, Conway TL, et al. Environmental interventions for eating and physical activity. A randomised controlled trial in middle schools. Am J Prev Med 2003;24:209-17.

28. Harris JR. Where is the child's environment? A group socialization theory of development. Psychol Rev 1995;102:458-89.

29. Birch LL. Effects of peer models' food choices and eating behaviours on preschoolers' food preferences. Child Dev 1980;51:489-96.

30. Greer RD, Dorow L, Williams G, et al. Peer-mediated procedures to induce swallowing and food acceptance in young children. J App/ Behav Anal 1991;24:783-90.
31. Hendy HM. Effectiveness of trained peer models to encourage food acceptance in preschool children. Appetite 2002;39:217-25.

32. Birch LL, Marlin DW. I don't like it; I never tried it: effects of exposure on two-yearold children's food preferences. Appetite 1982;3:353-60.

33. Birch LL, McPhee L, Shoba BC, et al. What kind of exposure reduces children's food neophobia? Looking vs. tasting. Appetite 1987;9:171-8.

34. Birch LL, Gunder L, Grimm-Thomas K, et al. Infants' consumption of a new food enhances acceptance of similar foods. Appetite 1998;30:283-95.

35. Sullivan SA, Birch LL: Pass the sugar, pass the salt: experience dictates preference. Dev. Psychol 1990;26:546-51.

36. Wardle J, Cooke LJ, Gibson EL, et al. Increasing children's acceptance of vegetables: a randomised trial of guidance to parents. Appetite 2003:40:155-62.

37. Wardle J, Herrera M-L, Cooke L, et al. Modifying children's food preferences: the effects of exposure and reward on acceptance of an unfamiliar vegetable. Eur J Clin Nutr 2003;57:341-8.

38. Birch LL. Preschool children's food preferences and consumption patterns. J Nutr Educ 1979;11:189-92.

39. Moe J, Roberts J, Moore L: Planning and running fruit tuck shops in primary schools. Health Educ 2001;101:61-8.

40. Moore L, Tapper K, Dennehy A, et al. Development and testing of a computerised 24-hour recall questionnaire measuring fruit and snack consumption among 9-11 year olds. Eur J Clin Nutr 2005;59:809-16.

41. Donner A, Klar N. Design and analysis of cluster randomization trials in health research. London: Arnold, 2000.

42. StataCorp. Stata statistical software: release 6.0. user's guide. College Station, TX: Stata Corporation, 1999

43. Flay B. Efficacy and effectiveness trials (and other phases of research) in the development of health promotion programs. Prev Med 1986;15:451-74.

44. Livingstone MBE, Robson PJ: Measurement of dietary intake in children. Proc Nutr Soc 2000;59:279-93.

45. Edmunds LD, Ziebland S. Development and validation of the Day in the Life Questionnaire (DILO) as a measure of fruit and vegetable questionnaire for 7-9 year olds. Health Educ Res 2002;17:211-20.

46. Neumark-Sztainer D, French SA, Hannan PJ, et al. School lunch and snacking patterns among high school students: associations with school food environment and policies. Int J Behav Nutr Phys Act 2005;2:14.

47. McLeroy K, Bibeau D, Steckler A. An ecological perspective on health promotion programs. Health Educ Behav 1988;15:351-377.

48. Lister-Sharp D, Chapman S, Stewart-Brown S, et al. Health promoting schools and health promotion in schools: two systematic reviews. Health Technol Assess 1999;3:22.

49. Summerbell CD, Waters E, Edmunds LD, et al. Interventions for preventing obesity in children. Cochrane Database Syst Rev 2005;3:CD001871. 